\title{
Characterization of biofilm production in different strains of Acinetobacter baumannii and the effects of chemical compounds on biofilm formation
}

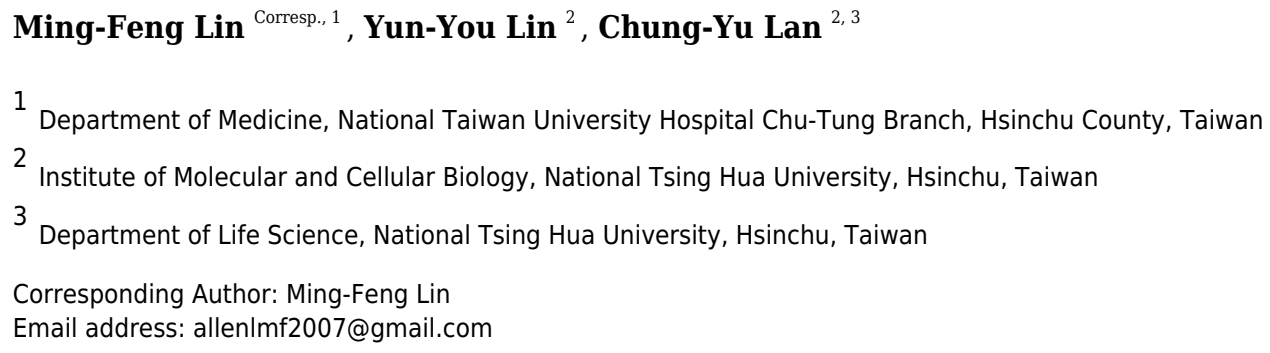

Acinetobacter baumannii, an important emerging pathogen of nosocomial infections, is known for its ability to form biofilms. Biofilm formation increases the survival rate of $A$. baumannii on dry surfaces and may contribute to its persistence in the hospital environment, which increases the probability of nosocomial infections and outbreaks. This study was undertaken to characterize the biofilm production of different strains of $A$. baumannii and the effects of chemical compounds, especially antibiotics, on biofilm formation. In this study, no statistically significant relationship was observed between the ability to form a biofilm and the antimicrobial susceptibility of the $A$. baumannii clinical isolates. Biofilm formation caused by A. baumannii ATCC 17978 after gene knockout of two-component regulatory system gene baeR, efflux pump genes emrA/emrB and outer membrane coding gene ompA revealed that all mutant strains had less biofilm formation than the wild-type strain, which was further supported by the images from scanning electron microscopy and confocal laser scanning microscopy. The addition of amikacin, colistin, LL-37 or tannic acid decreased the biofilm formation ability of $A$. baumannii. In contrast, the addition of lower subinhibitory concentration tigecycline increased the biofilm formation ability of $A$. baumannii. Minimum biofilm eradication concentrations of amikacin, imipenem, colistin, and tigecycline were increased obviously for both wild type and multidrug resistant clinical strain $A$. baumannii VGH2. In conclusion, the biofilm formation ability of $A$. baumannii varied in different strains, involved many genes and could be influenced by many chemical compounds. 
2 Characterization of biofilm production in different

3 strains of Acinetobacter baumannii and the effects of

4 chemical compounds on biofilm formation

5

6

7

8

9

10

11

12

13

14

15

\author{
Ming-Feng Lin ${ }^{1}$, Yun-You Lin ${ }^{2}$, Chung-Yu Lan ${ }^{2,3}$
}

${ }^{1}$ Department of Medicine, National Taiwan University Hospital Chu-Tung Branch, Hsinchu County, Taiwan

2 Institute of Molecular and Cellular Biology, National Tsing Hua University, Hsinchu, Taiwan

${ }^{3}$ Department of Life Science, National Tsing Hua University, Hsinchu, Taiwan

Corresponding Author:

Ming-Feng Lin ${ }^{1}$

No. 52, Chih Shan Road, Chutung Town, Hsinchu County 31064, Taiwan.

Email address: allenlmf2007@gmail.com

\section{Abstract}

Acinetobacter baumannii, an important emerging pathogen of nosocomial infections, is known for its ability to form biofilms. Biofilm formation increases the survival rate of $A$. baumannii on dry surfaces and may contribute to its persistence in the hospital environment, which increases the probability of nosocomial infections and outbreaks. This study was undertaken to characterize the biofilm production of different strains of $A$. baumannii and the effects of chemical compounds, especially antibiotics, on biofilm formation. In this study, no statistically significant relationship was observed between the ability to form a biofilm and the antimicrobial susceptibility of the $A$. baumannii clinical isolates. Biofilm formation caused by $A$. baumannii ATCC 17978 after gene knockout of two-component regulatory system gene baeR, efflux pump genes emrA/emrB and outer membrane coding gene ompA revealed that all mutant strains had less biofilm formation than the wild-type strain, which was further supported by the images from scanning electron microscopy and confocal laser scanning microscopy. The addition of amikacin, colistin, LL-37 or tannic acid decreased the biofilm formation ability of $A$. baumannii. In contrast, the addition of lower subinhibitory concentration tigecycline increased the biofilm formation ability of $A$. baumannii. Minimum biofilm eradication concentrations of amikacin, imipenem, colistin, and tigecycline were increased obviously for both wild type and multidrug resistant clinical strain $A$. baumannii VGH2. In conclusion, the biofilm formation ability of $A$. 
38

39

40

41

42

43

44

45

46

47

48

49

50

51

52

53

54

55

56

57

58

59

60

61

62

63

64

65

66

67

68

69

70

71

72

73

74

75

76

77

baumannii varied in different strains, involved many genes and could be influenced by many chemical compounds.

\section{Introduction}

A. baumannii, as an important emerging pathogen of nosocomial infection, is known for its ability to form biofilms (Longo, Vuotto \& Donelli 2014). Biofilm formation increases the survival rate of $A$. baumannii on dry surfaces and may contribute to its persistence in the hospital environment, increasing the probability of causing nosocomial infections and outbreaks (Espinal, Marti \& Vila 2012).

The mechanisms to explain the increased drug resistance of bacteria related with biofilms are various and at least included delayed penetration of the antimicrobial agents into the biofilm and reduced growth rate of the microorganisms within the biofilm (Donlan 2000). A positive correlation between biofilm formation and antimicrobial resistance in Acinetobacter baumannii has been confirmed (Badave \& Kulkarni 2015), although one study suggested an inverse relationship between biofilm production and meropenem resistance in nosocomial A. baumannii isolates (Perez 2015). The ability to form a biofilm may affect antibiotic susceptibility and clinical failure, even when the dose administered is in the susceptible range (Kim et al. 2015).

Modulation of biofilm formation is as diverse as the surface on which the bacteria reside and the cellular components involved in the programmed multi-step process (Gaddy \& Actis 2009). The regulation of biofilm formation is influenced by sensing bacterial cell density, the presence of different nutrients and the concentration of cations, which was through the two-component regulatory system BfmRS (Luo et al. 2015a). This transcriptional regulatory system activates the expression of the CsuA/BABCDE usher-chaperone assembly system responsible for the production of pili, which are needed for cell attachment and biofilm formation on polystyrene surfaces (Tomaras et al. 2008). Both biofilm-associated proteins and OmpA protein play a role in biofilm formation in A. baumannii (Loehfelm, Luke \& Campagnari 2008; Gaddy, Tomaras \& Actis 2009). Together, the regulation of biofilm formation is multifactorial, and many molecular mechanisms remain unidentified.

Although biofilm formation in bacteria has been studied extensively (Kalkanci \& TunÇCan 2019) and described in A. baumannii previously (Kim et al. 2015), the characteristics of biofilm production in clinical isolates from hospitals in Taiwan have seldom been well characterized. Therefore, we used the $A$. baumannii strains from our previous studies to examine the difference in biofilm formation among these strains with a modified XTT assay. In addition, we also closely observed biofilm formation using scanning electron microscopy (SEM) and confocal laser scanning microscopy (CLSM). These experiments were designed to understand the nature of biofilm production among the wild-type strain, mutant strains and clinical isolates of $A$. baumannii. To examine the impact of different compounds on biofilm formation and find potential candidates for anti-biofilm agents, different kinds of antibiotics, the antimicrobial peptide LL-37 and the iron chelating agent tannic acid, were chosen to test the relationship between their presence and biofilm production in A. baumannii. Finally, to understand how the 
78

79

80

81

82

83

84

85

86

87

88

89

90

91

92

93

94

95

96

97

98

99

100

101

102

103

104

105

106

107

108

109

110

111

112

113

114

115

116

117

presence of an $A$. baumannii biofilm influenced antimicrobial therapy, we determined the planktonic minimum inhibitory concentrations and minimum biofilm eradication concentrations. The result might help clinicians decide the optimal therapy while treating the infections caused by $A$. baumannii with a high biofilm-producing ability.

\section{Materials \& Methods}

\section{Bacterial strains}

All of the bacterial strains used in this study were isolates from our previous studies (Lin et al. 2014; Lin, Lin \& Lan 2015; Lin et al. 2015; Lin, Lin \& Lan 2017a; Lin et al. 2017b) or American Type Culture Collection (ATCC), as shown in Table 1. The studied strains contained quality control strain ATCC 19606, ATCC 17978 and 21 clinical isolates. Five antibioticinduced resistant strains from ATCC 17978 or tigecycline resistant clinical isolate ABhll were also included. Since biofilm formation is associated with antibiotic resistance and baeR as well as $e m r A / e m r B$ have been shown related with tigecycline and colistin resistance respectively in our previous studies (Lin et al. 2014; Lin, Lin \& Lan 2017a), so we also enrolled the mutant strains for these genes.

\section{Biofilm quantification}

Biofilm formation was performed in 24-well polystyrene plates as previously described with some modifications (Marti et al. 2011; Orsinger-Jacobsen et al. 2013; Kim et al. 2015). Biofilm formation was determined in Mueller Hinton Broth (MHB) using an initial $\mathrm{OD}_{600}$ of 0.01 , and the plates were incubated at $37^{\circ} \mathrm{C}$ for $24 \mathrm{~h}$ without shaking (24-well, $1 \mathrm{~mL}$ ). Two wells were left uninoculated and used as negative controls. The culture media was removed by inversion, and the wells were washed twice with phosphate buffered saline (PBS).

Both crystal violet and XTT assays show an excellent application for quantification of biofilms. The Crystal violet assay is cheap, easy and is usually used for the quantification of biofilms formed by microorganisms but XTT is more reliable and repeatable (Hendiani, AbdiAli \& Mohammadi 2014). In this study, XTT assay was used to measure the metabolic activity in order to estimate the burden of viable cells. The electron transport system in the cellular membrane of live bacteria reduces the XTT tetrazolium salt to XTT formazan, which results in a colorimetric change measured at $492 \mathrm{~nm}$ (Orsinger-Jacobsen et al. 2013). $250 \mu \mathrm{L}$ XTT solution $(0.0625 \mathrm{mg} / \mathrm{mL}$ XTT, $0.5 \mathrm{mM}$ menadione in PBS) was added to each well of 24 -well microtiter plate for $30 \mathrm{~min}$ at $37^{\circ} \mathrm{C}$. After incubation, $200 \mu \mathrm{L}$ of the XTT supernatant was transferred to a fresh 96-well plate, and the calorimetric absorbance was measured (OD $490 \mathrm{~nm}$ (XTT) biofilm) at 490 nm using iMarkTM Microplate Absorbance Reader (Bio-Rad laboratories, Inc. USA). The negative control $\left(\mathrm{OD}_{490 \mathrm{~nm}}\right.$ (XTT) control) was used to reduce the background absorbance optic density values in the XTT assay. Since different bacterial strains had different growth rates, the total cell numbers would be different at the end of incubation, thus influencing the total biofilm mass or metabolic activities. To correct the bias due to cell numbers, the $\mathrm{OD}_{595 \mathrm{~nm}}\left(\mathrm{OD}_{595 \mathrm{~nm} \text { (cells) }}\right)$ was determined to estimate the total cells in each corresponding well of 24-well microtiter plate 
118 after transferred to a new 96-well plate for optic density measurement. The ability to form a

119

120

121

122

123

124

125

126

127

128

129

130

131

132

133

134

135

136

137

138

139

140

141

142

143

144

145

146

147

148

149

150

151

152

153

154

155

156

157

biofilm was expressed using a biofilm formation index: $\left[\mathrm{BFI}=\left(\mathrm{OD}_{490 \mathrm{~nm}}\right.\right.$ (XTT) biofilm $-\mathrm{OD}_{490 \mathrm{~nm}}$ (XTT) control $/ \mathrm{OD}_{595 \mathrm{~nm} \text { (cells) }}$. The ODc was defined as three standard deviations above the mean OD of the negative control. Each isolate was classified as follows: non-biofilm producer: $\mathrm{OD} \leq \mathrm{ODc}$; weak biofilm producer: ODc $<\mathrm{OD} \leq 2 \times$ ODc; moderate biofilm producer: $2 \times$ ODc $<$ OD $\leq 4 \times$ ODc; or strong biofilm producer: OD $>4 \times$ ODc (Hu et al. 2016).

\section{Biofilm imaging}

Biofilms were examined by SEM and CLSM (Djeribi et al. 2012). For SEM examination, biofilms were developed at $37^{\circ} \mathrm{C}$ for $24 \mathrm{~h}$ in polystyrene coverslips placed into a 24-well plate with MHB containing bacterial cells $\left(\mathrm{OD}_{600 \mathrm{~nm}} 0.01\right)$ added. After fixed in $3.7 \%$ formaldehyde for $40 \mathrm{~min}$ at room temperature and then rinsed twice with PBS, further fixation was performed with $1 \%$ osmium tetroxide for $15 \mathrm{~min}$ at room temperature and then rinsed twice with PBS. The samples were then dehydrated by passing them through different concentrations of ethanol: $35 \%$, $50 \%, 70 \%, 80 \%$, and $95 \%$, each for $5 \mathrm{~min}$, followed by $100 \%$ ethanol twice for $10 \mathrm{~min}$ each time. The samples were then dried at $60^{\circ} \mathrm{C}$ for $24 \mathrm{~h}$. After being coated with gold-palladium (via sputter coating), the samples were examined under a bioscanning electron microscope (Hitachi, S-4700, Type II).

For CLSM examination, biofilms formation in polystyrene coverslips and fixation in $3.7 \%$ formaldehyde were the same as mentioned above. Then the samples were stained with a prepared $100 \mathrm{nM}$ solution of Syto-9 stain (Invitrogen, Carlsbad, CA) for 30 min (Luo et al. 2015b). Syto-9 stained biofilms were excited with a $488 \mathrm{~nm}$ solid-state laser, and fluorescence was captured between $500-550 \mathrm{~nm}$. The images of biofilms were rendered and assembled using appropriate computational software (ZEISS LSM780).

\section{Influence of antibiotics, LL-37 and tannic acid on biofilm formation}

The activity of the various antibiotics, including amikacin, imipenem, colistin and tigecycline, LL-37 and tannic acid, on bacterial growth was tested in 24-well microtiter plates containing the above compounds at different concentrations. The concentrations chosen for different compounds were based on individual MIC with two-fold serial dilution. However, if biofilm formation was not observed at the higher concentrations of compounds, then the lower concentration was adopted. Biofilm production was checked by the same method as described above. Finally, A. baumannii ATCC 17978 without any compound added was used as a control for biofilm formation to calculate the relative biofilm formation capacity (relative biofilm

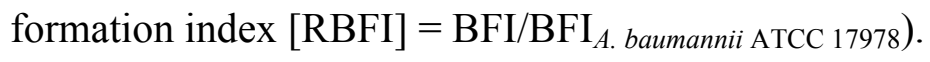

\section{Planktonic susceptibility test}

A planktonic susceptibility test was performed as previously described to determine the minimum inhibitory concentration (MIC) of A. baumannii (Lin et al. 2014). In brief, bacteria were inoculated into $1 \mathrm{~mL}$ cation-adjusted Mueller-Hinton Broth (CAMHB) (Sigma-Aldrich, St. 
158 Louis, MO) containing different concentrations of antibiotics, including amikacin, imipenem, 159 colistin and tigecycline, to reach $\approx 5 \times 10^{5} \mathrm{CFU} / \mathrm{mL}$, and the cultures were incubated at $37^{\circ} \mathrm{C}$ for $16024 \mathrm{~h}$. The lowest antibiotic concentration that completely inhibited bacterial growth was defined

161

162

163

164

165

166

167

168

169

170

171

172

173

174

175

176

177

178

179

180

181

182

183

184

185

186

187

188

189

190

191

192

193

194

195

196

197 as the minimum inhibitory concentration, and growth was determined by unaided eyes and by measuring optical densities using a spectrophotometer.

\section{Biofilm susceptibility test}

The biofilm susceptibility test was performed as previously described with some modifications (Kim et al. 2015). In brief, preparation of the antibiotic stock solution and preparation of the inoculum were the same as the method used in checking the MIC. Biofilm susceptibility tests were performed in flat-bottom, polystyrene cell-culture microtiter plates containing $5 \times 10^{5}$ $\mathrm{CFU} / \mathrm{mL}$ in MHB with final well volumes of $100 \mu \mathrm{L}$. The plates were incubated at $37^{\circ} \mathrm{C}$ without shaking. After $24 \mathrm{~h}$, all the suspension fluid was removed from the plates and then washed with PBS. Equal amounts of appropriate antibiotic dilutions were added. Twofold dilutions of the tested antibiotics in CAMHB were diluted from 256 to $0.125 \mu \mathrm{g} / \mathrm{mL}$. The tested antibiotic concentrations would be increased if necessary. Then, the plates were incubated at $37^{\circ} \mathrm{C}$ for $24 \mathrm{~h}$ without shaking. After $24 \mathrm{~h}$, inhibition of bacteria growth was determined by no turbidity observed by unaided eyes. Regrowth of bacteria was further determined by spot assay. The minimum biofilm eradication concentration (MBEC) represents the lowest drug concentration at which bacteria failed to regrow (Olson et al. 2002).

\section{Statistical analysis}

The comparison of biofilm formation, including BFI and RBFI, was analyzed using Student's ttest. All of the data were from three independent experiments and analyzed using Statistical Package for the Social Sciences version 16 (SPSS Inc., Chicago, IL, USA). $p<0.05$ was considered statistically significant.

\section{Results}

\section{Biofilm quantification and its relationship with the antimicrobial susceptibility}

Biofilm quantification of the 33 different strains of $A$. baumannii (Table 1), including 21 clinical isolates, by the biofilm formation index is presented in Fig. 1. There are obvious differences in biofilm formation among the clinical isolates of A. baumannii. Of the 22 clinical isolates including A. baumannii ATCC 17978, twenty isolates were strong biofilm producers ( $4 \times$ $\left.\mathrm{ODc}<\mathrm{OD}_{490 \mathrm{~nm}}\right)$ except VGH1 and CT11 $\left(2 \times \mathrm{ODc}^{2}<\mathrm{OD}_{490 \mathrm{~nm}} \leq 4 \times \mathrm{ODc}\right)$ were moderate biofilm producers (data shown in the raw data set).

The antimicrobial susceptibility of the clinical isolates in this study has been published previously (Lin et al. 2017b) as shown in Table S1. Susceptibility breakpoints to antimicrobial agents were determined by the MIC interpretive standards for Acinetobacter spp. of Clinical and Laboratory Standards Institute (CLSI. 2012). The MIC interpretive criteria for each individual antimicrobial agents except cefazolin, cefmetazole and tigecycline $(\mathrm{MIC} \mu \mathrm{g} / \mathrm{mL})(\mathrm{S}=$ susceptible, 
$198 \mathrm{I}=$ intermediate and $\mathrm{R}=$ resistant) are listed respectively as the following : Ampicillin/sulbactam 199 ( $\mathrm{S} \leq 8 / 4$, I 16/8 and $\mathrm{R} \geq 32 / 16)$; piperacillin/tazobactam $(\mathrm{S} \leq 16 / 4$, I 32/4-64/4 and $\mathrm{R} \geq 128 / 4)$; 200 cefotaxime ( $\mathrm{S} \leq 8, \mathrm{I} 16-32$ and $\mathrm{R} \geq 64)$; ceftazidime ( $\mathrm{S} \leq 8$, I 16 and $\mathrm{R} \geq 32$ ); cefepime ( $\mathrm{S} \leq 8$, I 20116 and $\mathrm{R} \geq 32$ ); imipenem ( $\mathrm{S} \leq 4$, I 8 and $\mathrm{R} \geq 16$ ); meropenem $(\mathrm{S} \leq 4$, I 8 and $\mathrm{R} \geq 16$ ); amikacin 202 ( $\mathrm{S} \leq 16$, I 32 and $\mathrm{R} \geq 64)$; gentamicin $(\mathrm{S} \leq 4$, I 8 and $\mathrm{R} \geq 16)$; ciprofloxacin $(\mathrm{S} \leq 1$, I 2 and $\mathrm{R} \geq 4)$; 203 levofloxacin ( $\mathrm{S} \leq 2$, I 4 and $\mathrm{R} \geq 8)$; trimethoprim/sulfamethoxazole $(\mathrm{S} \leq 2 / 38$ and $\mathrm{R} \geq 4 / 76)$. $A$.

204 baumannii is naturally resistant to cefazolin, whereas the isolates of $A$. baumannii with 205 cefmetazole MICs of $\geq 32 \mu \mathrm{g} / \mathrm{mL}$ are considered resistant (Jones et al. 1986). The provisional 206 MIC breakpoints for tigecycline are $\leq 2,4$ and $\geq 8 \mu \mathrm{g} / \mathrm{mL}$ to designate susceptible, intermediate 207 and resistant strains, respectively (Pachon-Ibanez et al. 2004). All of the 21 A. baumannii clinical

208

209

210

211

212

213

214

215

216

217

218

219

220

221

222

223

224

225

226

227

228

229

230

231

232

233

234

235

236

237 isolates are not susceptible to many of the tested antimicrobial agents. Although ATCC 17978 is the least resistant strain among the isolates studied, its BFI ranked second. Two isolates, VGH2 and $\mathrm{VGH} 7$, are pan-drug resistant. However, their biofilm formation ability BFI differed with VGH2 ranking first and VGH7 ranking sixteenth. It seems the capacity of biofilm production does not relate to antimicrobial susceptibility as shown in Table S1. To validate the inference, the correlation between biofilm formation ability and resistance to the 15 antimicrobial agents in A. baumannii was analyzed using the Wilcoxon rank-sum test. Fig. 2 depicts the box plots with the comparison of the biofilm formation indices of the susceptible and resistant strains to the individual antibiotics. It reveals no relationship with statistical significance $(p>0.05)$ between the ability to form biofilm and the antimicrobial susceptibility of the $A$. baumannii clinical isolates.

\section{Biofilm formation by $A$. baumannii ATCC 17978 after baeR, emrA, emrB and ompA gene knockout}

Many proteins, including two-component regulatory system BfmRS (Luo et al. 2015a), CsuA/BABCDE usher-chaperone assembly system (Tomaras et al. 2008), biofilm-associated proteins (Loehfelm, Luke \& Campagnari 2008), OmpA protein (Gaddy, Tomaras \& Actis 2009), AdeFGH (He et al. 2015) and blaPER (Lee et al. 2008), have been demonstrated to be related with biofilm formation in A. baumannii. To understand the scope of involvement further, biofilm formation caused by A. baumannii ATCC 17978 after gene knockout of another two-component regulatory system gene baeR, efflux pump genes emrA/emrB and ompA is compared as shown in Fig. 3A. The $\triangle b a e R, \triangle e m r A, \triangle e m r B$ and $\triangle o m p A$ mutant strains all had less biofilm formation than the wild type strain. This result is further confirmed by the SEM and CLSM images shown in Fig. 3B and 3C, respectively. Of these three categories of genes, omp $A$ knockout led to the most marked decrease biofilm formation in A. baumannii. The SEM figure of $\triangle o m p A$ strain shows that only few cells are clustered and its images of CLSM exhibit the thinnest biofilm. Although the influence on biofilm formation reduction after baeR, emrA, or emrB gene knockout was not so obvious as the $\triangle$ omp $A$ strain, the degree of decrease was still statistically significant while being compared with the ATCC 17978 strain $(p<0.05$ for $\triangle b a e R, p<0.01$ for $\triangle e m r A$, and $p<0.001$ for $\triangle e m r B$ ). 


\section{Influence of different compounds on biofilm formation}

239 Table 2 presents minimum inhibitory concentrations (MICs) of A. baumannii ATCC 17978 and $240 \mathrm{VGH} 2$ to amikacin, imipenem, colistin, tigecycline, LL-37 and tannic acid. The influence of

241 different compounds, including amikacin, imipenem, colistin, tigecycline, LL-37 and tannic acid, 242 on biofilm formation in A. baumannii ATCC 17978 and VGH2 is shown in Fig. 4 and Fig. 5.

243 Amikacin, imipenem, colistin and LL-37 were tested at 1/4, 1/2 and $1 \mathrm{x}$ MIC whereas tigecycline 244 was tested at 1/16, 1/8, 1/4 x MIC. Since tannic acid had very high MIC $(>300 \mu \mathrm{g} / \mathrm{mL})$, the 245 concentrations of 200,100 and $50 \mu \mathrm{g} / \mathrm{mL}$ were chosen arbitrarily for testing. The addition of $246 \operatorname{amikacin}(>0.5 \mu \mathrm{g} / \mathrm{mL})$, colistin $(>0.5 \mu \mathrm{g} / \mathrm{mL})$, LL-37 $(>4 \mu \mathrm{g} / \mathrm{mL})$, or tannic acid $(>50 \mu \mathrm{g} / \mathrm{mL})$ 247 decreased the biofilm formation ability of $A$. baumannii ATCC 17978, whereas the addition of 248 amikacin $(>256 \mu \mathrm{g} / \mathrm{mL})$, imipenem $(>4 \mu \mathrm{g} / \mathrm{mL})$, colistin $(>0.125 \mu \mathrm{g} / \mathrm{mL})$, LL-37 $(>2 \mu \mathrm{g} / \mathrm{mL})$, 249 or tannic acid $(>50 \mu \mathrm{g} / \mathrm{mL})$ decreased the biofilm formation ability of VGH2. In contrast, the 250 addition of tigecycline increased the biofilm formation ability of $A$. baumannii ATCC 17978 ( $>$ 251

252

253

254

255

256

257

258

259 $62.5 \mathrm{ng} / \mathrm{mL})$ and VGH2 $(>0.5 \mu \mathrm{g} / \mathrm{mL})$. Figure 6 presents the SEM and CLSM images of biofilm formation by $A$. baumannii ATCC 17978 in the presence of $1 \mu \mathrm{g} / \mathrm{mL}$ colistin or $125 \mathrm{ng} / \mathrm{mL}$ tigecycline. With $1 \mu \mathrm{g} / \mathrm{mL}$ colistin added to the ATCC 17978 strain, the SEM image shows the cells become scattered and the CLSM images exhibit decreased thickness of biofilm. In contrast, $125 \mathrm{ng} / \mathrm{mL}$ tigecycline exposure has the opposite impact on biofilm formation of $A$. baumannii ATCC 17978. Both of the SEM and CLSM images validated the findings of biofilm quantification by RBFI analysis (Fig. 4 and Fig. 5).

\section{MICs and MBECs of $\boldsymbol{A}$. baumannii ATCC 17978 and VGH2}

260

261 Besides MICs, MBECs of $A$. baumannii ATCC 17978 and VGH2 to amikacin, imipenem, colistin and tigecycline is also shown in Table 2. In this study, the MIC values for antimicrobials were determined using a broth microdilution assay. The ATCC 17978 strain had low MICs to all

263 of the four tested antimicrobial agents, whereas the VGH2 strain had higher MICS for amikacin

264 $(1024 \mu \mathrm{g} / \mathrm{mL})$ and imipenem $(16 \mu \mathrm{g} / \mathrm{mL})$. When biofilms cells of the same strains were tested, MBECs rose astonishingly with at least fourfold higher relative to the planktonic MICs. Of all the four antibiotics tested, colistin had the most obvious MBEC increase from 0.5 to $>8192$

268 $\mu \mathrm{g} / \mathrm{mL}$ for VGH2. This result suggested that biofilm cells of bacteria would become more 269

270 resistant to tested antibiotics according to MBEC.

271

\section{Discussion}

272

High variability in biofilm formation exists among the clinical isolates of $A$. baumannii

273 (Wroblewska et al. 2008). In a previous study that examined 86 clinical isolates of $A$. baumannii, clinical isolates exhibited an enhanced biofilm formation ability relative to a standard $A$.

275 baumannii strain (ATCC 19606) (Kim et al. 2015). Interestingly, only A. baumannii VGH2 has

276 better biofilm formation ability than the standard A. baumannii strain (ATCC 17978) in this 277 study. However, Kim et al. used crystal violet to measure the biomass of biofilm whereas we measured the metabolic activity in order to estimate the burden of viable biofilm cells by 
278 tetrazolium salt XTT reduction assay instead because the XTT assay is the test most commonly 279 used to estimate viable biofilm growth and to examine the impact of biofilm therapies (Nett et al. 280 2011). One previous study about candidal biofilm showed the better reproducibility of the XTT 281 assay compared with that of the crystal violet method led the authors to conclude that the former 282 is more reliable (Jin et al. 2003). However, using a metabolic activity assay for measuring 283 antibiotic activity against biofilm suffers from the limitation that usually the absorbance or 284 fluorescence signal decreases in proportion to the number of bacteria only on a limited range of 285 colony forming units (CFUs). Statistical analyses showed that XTT activity was linearly 286 associated with the log of the cell concentration over the cell concentration range tested (from 2

287

288

289

290

291

292

293

294

295

296

297

298

299

300

301

302

303

304

305

306

307

308

309

310

311

312

313

314

315

316

317 X $10^{5}$ to $10^{8}$ cells $/ \mathrm{ml}$ ), implying XTT activity can be used as an indicator of cell numbers in a cell suspension (Jin et al. 2003; Orsinger-Jacobsen et al. 2013). Although we didn't determine the zone of linearity in this study, all of the absorbance $\mathrm{OD}_{595}$ values, even in the presence of subinhibitory antibiotic concentrations, were more than 0.1 (data shown in the raw data set), which indicated that cells were present more than $10^{5}$. Therefore, the XTT assay in this study was presumed to be applicable in measuring the biofilm formation of $A$. baumannii. On the other hand, major differences in metabolic activity can be observed when comparing several bacterial isolates from the same species (Zimmermann et al. 2015), so that differences in XTT signal could rely simply on difference in metabolic activity. In this study, the influence of chemical compounds on biofilm formation of ATCC 17978 or VGH2 was compared to itself. Therefore, this phenomenon would not change the main findings of this study.

In this study, all of the 21 A. baumannii clinical isolates could form biofilms. However, the clone relatedness and the ability of biofilm formation were not further explored. One previous study reported higher ability of biofilm formation was found for the strains assigning to multilocus sequence typing (MLST) sequence type 2 (ST2), ST25 and ST78 (Giannouli et al. 2013). But in another study the sporadic strains showed significantly higher biofilm-forming capacity than the epidemic isolates assigning to ST2 (Hu et al. 2016). It seems the biofilmforming capacity in various sequence types of $A$. baumannii needs further experiments to clarify.

A few studies have investigated the role of RND efflux pumps, including AdeABC, AdeIJK and AdeFGH, in A. baumannii biofilm formation (He et al. 2015; Yoon et al. 2015). The role of efflux pumps in $A$. baumannii biofilm formation has been suggested in whole transcriptome analysis of biofilm and planktonic cells (Rumbo-Feal et al. 2013), although EmrAB was not implicated in gene expression change of biofilm cells. However, emrA and emrB genes have been demonstrated related with biofilm formation in other bacteria. Escherichia coli mutant strains lacking the efflux emrA and emrB were reported to display enhanced biofilm growth compared with control (Bay et al. 2017), where the deletion of the efflux genes emrAB in Salmonella enterica serovars resulted in decreased biofilm formation compared with wild type strain (Baugh et al. 2012). In this study, the efflux pump EmrAB was found to be associated with biofilm formation in A. baumannii for the first time. Although we have demonstrated that EmrAB contributes to adaptation to osmotic stress and resistance to colistin in A. baumannii (Lin, Lin \& Lan 2017a), its role in biofilm formation still needs to be clarified. 
Besides emrA, emrB and ompA genes implicated in biofilm formation of $A$. baumannii in this study, deletion of two-component system gene baeR led to decreased biofilm formation. Deleting baeR of $A$. baumannii results in vulnerable to certain chemicals, especially tigecycline and tannic acid (Lin et al. 2014; Lin, Lin \& Lan 2015). In addition to involvement of disposing chemicals, two-component signal transduction system is also regarded as a major strategy for connecting input stimuli to biofilm formation (Liu et al. 2018). The current proposed model associates low intracellular levels of c-di-GMP with a planktonic lifestyle, whereas high c-di-GMP levels are associated with biofilm formation. However, it has been demonstrated that the BaeSR response in $E$. coli does not influence biofilm formation, nor is it involved in indole-mediated inhibition of biofilm formation (Leblanc, Oates \& Raivio 2011). To investigate the mechanism for biofilm formation decrease after baeR deletion and clarify the true role of BaeSR in biofilm formation of A. baumannii, a secondary messenger c-di-GMP concentration in A. baumannii needs to be measured in the future research since c-di-GMP is a well-known intracellular messenger molecule that affects biofilm formation.

Exposure to aminoglycoside and subinhibitory concentrations of imipenem is associated with biofilm-forming A. baumannii isolates (Rodríguez-Baño et al. 2008; Nucleo et al. 2009). In two pairs of clinical colistin-susceptible/colistin-resistant (Csts/Cstr) A. baumannii strains, the Cstr strains showed significantly decreased biofilm formation in static and dynamic assays $(p<0.001)$ and lower relative fitness $(p<0.05)$ compared with those of the Csts counterparts (Dafopoulou et al. 2015). We found that $A$. baumannii ATCC 17978 decreased biofilm formation upon exposure to subinhibitory concentrations of amikacin, imipenem and colistin. In this study, tannic acid and LL-37 at a concentration below its MIC can decrease biofilm formation, which might occur by causing structural damage to the $A$. baumannii biofilm (Shi et al. 2014). One previous study has demonstrated increased biofilm formation of Staphylococcus epidermidis after sub-MIC tigecycline treatment (both at 0.25 and $0.5 \mathrm{MIC}$ ) by producing increased expression of the icaA (production of transmembrane protein), altE (encoding autolysin related with adhesion) and $\operatorname{sig} B$ (biofilm stability) genes and by affecting biofilm architecture in the isolates (Szczuka, Jablonska \& Kaznowski 2017). To explore the mechanism by which sub-MIC tigecycline increased the biofilm formation of $A$. baumannii, more future relevant studies are needed.

Wang et al. have shown that the minimal bactericidal concentrations for biofilm-embedded cells of the tested isolates were more than 50-fold higher than those for their planktonic cells (Wang et al. 2016). The lowest biofilm inhibitory concentration (BIC) value of clinical multidrug resistant $A$. baumannii (MDRAB) isolates for colistin was 32 -fold the $\mathrm{MIC}_{90}$ (minimum inhibitory concentration for $90 \%$ of the isolates) value, and $\mathrm{BIC}_{90}$ values were found to be 512 fold the $\mathrm{MIC}_{90}$ value (Milletli Sezgin, Coban \& Gunaydin 2013). This result is compatible with those in this study. Because treatment for biofilm-forming MDRAB infection has become more difficult, several regimens have been proposed as anti-biofilm treatment for A. baumannii infection. Treatment with imipenem and rifampicin individually or in combination has obvious anti-biofilm effects (Wang et al. 2014). Song et al. demonstrated that tigecycline and colistinrifampicin are effective for the prevention of or reduction in biofilm formation caused by $A$. 
358

359

360

361

362

363

364

365

366

367

368

369

370

371

372

373

374

375

376

377

378

379

380

381

382

383

384

385

386

387

388

389

390

391

392

393

394

395

396

397

398

399

baumannii strains (Song \& Cheong 2015). However, the influence of tigecycline on biofilm formation of $A$. baumannii is contrary to the results of this study. Meropenem plus sulbactam exhibited synergism against biofilm-embedded carbapenem-resistant $A$. baumannii and caused significantly more damage to biofilm architecture than any of the agents used alone (Wang et al. 2016).

The images of SEM and CLSM were used in this study to support the findings by XTT assay about the impact of gene knockout and adding antibiotics on biofilm formation, but no live-dead stain was performed. Live-dead stain consists of SYTO9, which stains live cells green, and propidium iodide (PI), which stains dead cells red (Richmond et al. 2016). This allows live versus dead cells to be detected and is more informative. Although we made an effort to characterize biofilm production of $A$. baumannii in different conditions, there were still some limitations in this study. As previously described, the interplay of these related genes in biofilm formation of A. baumannii and key secondary messenger c-di-GMP determination were not explored further. Besides, because the blood or tissue concentrations produced by infusions of the studied antimicrobials were not determined, it is hard to infer that the in vitro results will apply to the in vivo condition.

\section{Conclusions}

In this study, the efflux pump gene emrA/emrB and two-component system gene baeR were found to be associated with biofilm formation and sub-MIC tigecycline led to increased biofilm formation in A. baumannii for the first time. In conclusion, the biofilm formation ability of $A$. baumannii was diverse in different strains, involved many genes and is influenced by many chemical compounds. The minimum biofilm eradication concentrations of all the tested antibiotics were increased for both the wild-type and clinical isolate of multidrug resistant $A$. baumannii VGH2.

\section{References}

Badave GK, and Kulkarni D. 2015. Biofilm producing multidrug resistant Acinetobacter baumannii: an emerging challenge. Journal of clinical and diagnostic research 9:DC08-10 DOI: $10.7860 / j \mathrm{jdr} / 2015 / 11014.5398$.

Baugh S, Ekanayaka AS, Piddock LJ, and Webber MA. 2012. Loss of or inhibition of all multidrug resistance efflux pumps of Salmonella enterica serovar typhimurium results in impaired ability to form a biofilm. The Journal of antimicrobial chemotherapy 67:2409-2417 DOI: $10.1093 / \mathrm{jac} / \mathrm{dks} 228$.

Bay DC, Stremick CA, Slipski CJ, and Turner RJ. 2017. Secondary multidrug efflux pump mutants alter Escherichia coli biofilm growth in the presence of cationic antimicrobial compounds. Research in microbiology 168:208-221 DOI: 10.1016/j.resmic.2016.11.003.

CLSI. 2012. Performance Standards for Antimicrobial Susceptibility Testing; Twenty-Second Informational Supplement. CLSI document M100-S22. Wayne, PA: Clinical and Laboratory Standards Institute; 2012. 
400

401

402

403

404

405

406

407

408

409

410

411

412

413

414

415

416

417

418

419

420

421

422

423

424

425

426

427

428

429

430

431

432

433

434

435

436

437

438

439

440

441

442

443

444

Dafopoulou K, Xavier BB, Hotterbeekx A, Janssens L, Lammens C, De E, Goossens H, Tsakris A, Malhotra-Kumar S, and Pournaras S. 2015. Colistin-resistant Acinetobacter baumannii clinical strains with deficient biofilm formation. Antimicrobial agents and chemotherapy 60:1892-1895 DOI: 10.1128/aac.02518-15.

Djeribi R, Bouchloukh W, Jouenne T, and Menaa B. 2012. Characterization of bacterial biofilms formed on urinary catheters. American journal of infection control 40:854-859 DOI: 10.1016/j.ajic.2011.10.009.

Donlan RM. 2000. Role of biofilms in antimicrobial resistance. ASAIO Journal 46:S47-52 DOI: 10.1097/00002480-200011000-00037.

Espinal P, Marti S, and Vila J. 2012. Effect of biofilm formation on the survival of Acinetobacter baumannii on dry surfaces. The Journal of hospital infection 80:56-60 DOI: 10.1016/j.jhin.2011.08.013.

Gaddy JA, and Actis LA. 2009. Regulation of Acinetobacter baumannii biofilm formation. Future microbiology 4:273-278 DOI: 10.2217/fmb.09.5.

Gaddy JA, Tomaras AP, and Actis LA. 2009. The Acinetobacter baumannii 19606 OmpA protein plays a role in biofilm formation on abiotic surfaces and in the interaction of this pathogen with eukaryotic cells. Infection and immunity 77:3150-3160 DOI: 10.1128/IAI.00096-09.

Giannouli M, Antunes LC, Marchetti V, Triassi M, Visca P, and Zarrilli R. 2013. Virulence-related traits of epidemic Acinetobacter baumannii strains belonging to the international clonal lineages I-III and to the emerging genotypes ST25 and ST78. BMC infectious diseases 13:282 DOI: 10.1186/1471-2334-13-282.

He X, Lu F, Yuan F, Jiang D, Zhao P, Zhu J, Cheng H, Cao J, and Lu G. 2015. Biofilm formation caused by clinical Acinetobacter baumannii isolates is associated with overexpression of the AdeFGH efflux pump. Antimicrobial agents and chemotherapy 59:4817-4825 DOI: 10.1128/aac.00877-15.

Hendiani S, Abdi-Ali A, and Mohammadi P. 2014. Comparison of two methods for quantification of Acinetobacter baumannii biofilm formation. Biological journal of microorganism 2:51-56.

Hu Y, He L, Tao X, Meng F, and Zhang J. 2016. Biofilm may not be necessary for the epidemic spread of Acinetobacter baumannii. Scientific reports 6:32066 DOI: 10.1038/srep32066.

Jin Y, Yip HK, Samaranayake YH, Yau JY, and Samaranayake LP. 2003. Biofilm-forming ability of Candida albicans is unlikely to contribute to high levels of oral yeast carriage in cases of human immunodeficiency virus infection. Journal of clinical microbiology 41:29612967 DOI: 10.1128/jcm.41.7.2961-2967.2003.

Jones RN, Barry AL, Fuchs PC, and Thornsberry C. 1986. Antimicrobial activity of cefmetazole (CS-1170) and recommendations for susceptibility testing by disk diffusion, dilution, and anaerobic methods. Journal of clinical microbiology 24:1055-1059.

Kalkanci A, and TunÇCan Ö. 2019. Biofilm related infection: diagnosis, treatment and prevention. Mediterranean journal of infection microbes and antimicrobials (in press) DOI: 10.4274/mjima.galenos.2019.2019.18.

Kim HA, Ryu SY, Seo I, Suh SI, Suh MH, and Baek WK. 2015. Biofilm formation and colistin susceptibility of Acinetobacter baumannii isolated from Korean nosocomial samples. Microbial drug resistance 21:452-457 DOI: 10.1089/mdr.2014.0236. 
445 Leblanc SK, Oates CW, and Raivio TL. 2011. Characterization of the induction and cellular

446

447

448

449

450

451

452

453

454

455

456

457

458

459

460

461

462

463

464

465

466

467

468

469

470

471

472

473

474

475

476

477

478

479

480

481

482

483

484

485

486

487

488 role of the BaeSR two-component envelope stress response of Escherichia coli. Journal of bacteriology 193:3367-3375 DOI: 10.1128/JB.01534-10.

Lee HW, Koh YM, Kim J, Lee JC, Lee YC, Seol SY, Cho DT, and Kim J. 2008. Capacity of multidrug-resistant clinical isolates of Acinetobacter baumannii to form biofilm and adhere to epithelial cell surfaces. Clinical microbiology and infection 14:49-54 DOI: 10.1111/j.14690691.2007.01842.x.

Lin MF, Lin YY, and Lan CY. 2015. The role of the two-component system baesr in disposing chemicals through regulating transporter systems in Acinetobacter baumannii. PloS one 10:e0132843 DOI: 10.1371/journal.pone.0132843.

Lin MF, Lin YY, and Lan CY. 2017a. Contribution of EmrAB efflux pumps to colistin resistance in Acinetobacter baumannii. Journal of microbiology 55:130-136 DOI: 10.1007/s12275-017-6408-5.

Lin MF, Lin YY, Tu CC, and Lan CY. 2017b. Distribution of different efflux pump genes in clinical isolates of multidrug-resistant Acinetobacter baumannii and their correlation with antimicrobial resistance. Journal of microbiology, immunology, and infection 50:224-231 DOI: 10.1016/j.jmii.2015.04.004.

Lin MF, Lin YY, Yeh HW, and Lan CY. 2014. Role of the BaeSR two-component system in the regulation of Acinetobacter baumannii ade $A B$ genes and its correlation with tigecycline susceptibility. BMC microbiology 14:119 DOI: 10.1186/1471-2180-14-119.

Lin MF, Tsai PW, Chen JY, Lin YY, and Lan CY. 2015. OmpA binding mediates the effect of antimicrobial peptide LL-37 on Acinetobacter baumannii. PloS one 10:e0141107 DOI: 10.1371/journal.pone.0141107.

Liu C, Sun D, Zhu J, and Liu W. 2018. Two-component signal transduction systems: a major strategy for connecting input stimuli to biofilm formation. Frontiers in microbiology 9:3279 DOI: $10.3389 /$ fmicb.2018.03279.

Loehfelm TW, Luke NR, and Campagnari AA. 2008. Identification and characterization of an Acinetobacter baumannii biofilm-associated protein. Journal of bacteriology 190:1036-1044 DOI: 10.1128/jb.01416-07.

Longo F, Vuotto C, and Donelli G. 2014. Biofilm formation in Acinetobacter baumannii. The new microbiologica 37:119-127.

Luo LM, Wu LJ, Xiao YL, Zhao D, Chen ZX, Kang M, Zhang Q, and Xie Y. 2015a. Enhancing pili assembly and biofilm formation in Acinetobacter baumannii ATCC19606 using non-native acyl-homoserine lactones. BMC microbiology 15:62 DOI: 10.1186/s12866015-0397-5.

Luo TL, Rickard AH, Srinivasan U, Kaye KS, and Foxman B. 2015b. Association of blaOXA-23 and bap with the persistence of Acinetobacter baumannii within a major healthcare system. Frontiers in microbiology 6:182 DOI: 10.3389/fmicb.2015.00182.

Marti S, Rodriguez-Bano J, Catel-Ferreira M, Jouenne T, Vila J, Seifert H, and De E. 2011. Biofilm formation at the solid-liquid and air-liquid interfaces by Acinetobacter species. $B M C$ research notes 4:5 DOI: 10.1186/1756-0500-4-5.

Milletli Sezgin F, Coban AY, and Gunaydin M. 2013. Investigation of biofilm formation in Acinetobacter baumannii isolates and their colistin susceptibilities in biofilm. International journal of antimicrobial agents 41:199 DOI: 10.1016/j.ijantimicag.2012.10.003.

PeerJ reviewing PDF | (2019:10:42050:4:0:NEW 20 Mar 2020) 
489

490

491

492

493

494

495

496

497

498

499

500

501

502

503

504

505

506

507

508

509

510

511

512

513

514

515

516

517

518

519

520

521

522

523

524

525

526

527

528

529

530

531

532

533

534

Nett JE, Cain MT, Crawford K, and Andes DR. 2011. Optimizing a Candida biofilm microtiter plate model for measurement of antifungal susceptibility by tetrazolium salt assay. Journal of clinical microbiology 49:1426-1433 DOI: 10.1128/jcm.02273-10.

Nucleo E, Steffanoni L, Fugazza G, Migliavacca R, Giacobone E, Navarra A, Pagani L, and Landini P. 2009. Growth in glucose-based medium and exposure to subinhibitory concentrations of imipenem induce biofilm formation in a multidrug-resistant clinical isolate of Acinetobacter baumannii. BMC microbiology 9:270 DOI: 10.1186/1471-2180-9-270.

Olson ME, Ceri H, Morck DW, Buret AG, and Read RR. 2002. Biofilm bacteria: formation and comparative susceptibility to antibiotics. Canadian journal of veterinary research 66:8692.

Orsinger-Jacobsen SJ, Patel SS, Vellozzi EM, Gialanella P, Nimrichter L, Miranda K, and Martinez LR. 2013. Use of a stainless steel washer platform to study Acinetobacter baumannii adhesion and biofilm formation on abiotic surfaces. Microbiology 159:2594-2604 DOI: 10.1099/mic.0.068825-0.

Pachon-Ibanez ME, Jimenez-Mejias ME, Pichardo C, Llanos AC, and Pachon J. 2004. Activity of tigecycline (GAR-936) against Acinetobacter baumannii strains, including those resistant to imipenem. Antimicrobial agents and chemotherapy 48:4479-4481 DOI: 10.1128/aac.48.11.4479-4481.2004.

Perez LR. 2015. Acinetobacter baumannii displays inverse relationship between meropenem resistance and biofilm production. Journal of chemotherapy 27:13-16 DOI: 10.1179/1973947813y.0000000159.

Richmond GE, Evans LP, Anderson MJ, Wand ME, Bonney LC, Ivens A, Chua KL, Webber MA, Sutton JM, Peterson ML, and Piddock LJ. 2016. The Acinetobacter baumannii two-component system aders regulates genes required for multidrug efflux, biofilm formation, and virulence in a strain-specific manner. mBio 7:e00430-00416 DOI: 10.1128/mBio.00430-16.

Rodríguez-Baño J, Martí S, Soto S, Fernández-Cuenca F, Cisneros JM, Pachón J, Pascual A, Martínez-Martínez L, McQueary C, Actis LA, Vila J, and Infections. SGftSoN. 2008. Biofilm formation in Acinetobacter baumannii: associated features and clinical implications. Clinical microbiology and infection 14:276-278 DOI: 10.1111/j.1469-0691.2007.01916.x.

Rumbo-Feal S, Gomez MJ, Gayoso C, Alvarez-Fraga L, Cabral MP, Aransay AM, Rodriguez-Ezpeleta N, Fullaondo A, Valle J, Tomas M, Bou G, and Poza M. 2013. Whole transcriptome analysis of Acinetobacter baumannii assessed by RNA-sequencing reveals different mRNA expression profiles in biofilm compared to planktonic cells. PloS one 8:e72968 DOI: 10.1371/journal.pone.0072968.

Shi P, Gao Y, Lu Z, and Yang L. 2014. Effect of antibacterial peptide LL-37 on the integrity of Acinetobacter baumannii biofilm. Nan fang yi ke da xue xue bao 34:426-429.

Song JY, and Cheong HJ. 2015. In vitro comparison of anti-biofilm effects against carbapenem-resistant Acinetobacter baumannii: imipenem, colistin, tigecycline, rifampicin and combinations. Infection \& chemotherapy 47:27-32 DOI: 10.3947/ic.2015.47.1.27.

Szczuka E, Jablonska L, and Kaznowski A. 2017. Effect of subinhibitory concentrations of tigecycline and ciprofloxacin on the expression of biofilm-associated genes and biofilm structure of Staphylococcus epidermidis. Microbiology 163:712-718 DOI: 10.1099/mic.0.000453.

Tomaras AP, Flagler MJ, Dorsey CW, Gaddy JA, and Actis LA. 2008. Characterization of a two-component regulatory system from Acinetobacter baumannii that controls biofilm

Peer) reviewing PDF | (2019:10:42050:4:0:NEW 20 Mar 2020) 
formation and cellular morphology. Microbiology 154:3398-3409 DOI: 10.1099/mic.0.2008/019471-0.

Wang Y, Bao W, Guo N, Chen H, Cheng W, Jin K, Shen F, Xu J, Zhang Q, Wang C, An Y, Zhang K, Wang F, and Yu L. 2014. Antimicrobial activity of the imipenem/rifampicin combination against clinical isolates of Acinetobacter baumannii grown in planktonic and biofilm cultures. World journal of microbiology \& biotechnology 30:3015-3025 DOI: 10.1007/s11274-014-1728-7.

Wang YC, Kuo SC, Yang YS, Lee YT, Chiu CH, Chuang MF, Lin JC, Chang FY, and Chen TL. 2016. Individual or combined effects of meropenem, imipenem, sulbactam, colistin, and tigecycline on biofilm-embedded Acinetobacter baumannii and biofilm architecture. Antimicrobial agents and chemotherapy 60:4670-4676 DOI: 10.1128/aac.0055116.

Wroblewska MM, Sawicka-Grzelak A, Marchel H, Luczak M, and Sivan A. 2008. Biofilm production by clinical strains of Acinetobacter baumannii isolated from patients hospitalized in two tertiary care hospitals. FEMS immunology and medical microbiology 53:140-144 DOI: 10.1111/j.1574-695X.2008.00403.X.

Yoon EJ, Chabane YN, Goussard S, Snesrud E, Courvalin P, De E, and Grillot-Courvalin C. 2015. Contribution of resistance-nodulation-cell division efflux systems to antibiotic resistance and biofilm formation in Acinetobacter baumannii. mBio 6:e00309-00315. DOI: 10.1128/mBio.00309-15.

Zimmermann M, Escrig S, Hubschmann T, Kirf MK, Brand A, Inglis RF, Musat N, Muller S, Meibom A, Ackermann M, and Schreiber F. 2015. Phenotypic heterogeneity in metabolic traits among single cells of a rare bacterial species in its natural environment quantified with a combination of flow cell sorting and NanoSIMS. Frontiers in microbiology 6:243 DOI: $10.3389 /$ fmicb.2015.00243. 
Figure 1

Biofilm quantification of the 33 different strains, including 21 clinical isolates of $A$. baumannii (highlighted by asterisk markers).

There are obvious differences in biofilm formation among the clinical isolates of $A$. baumannii.

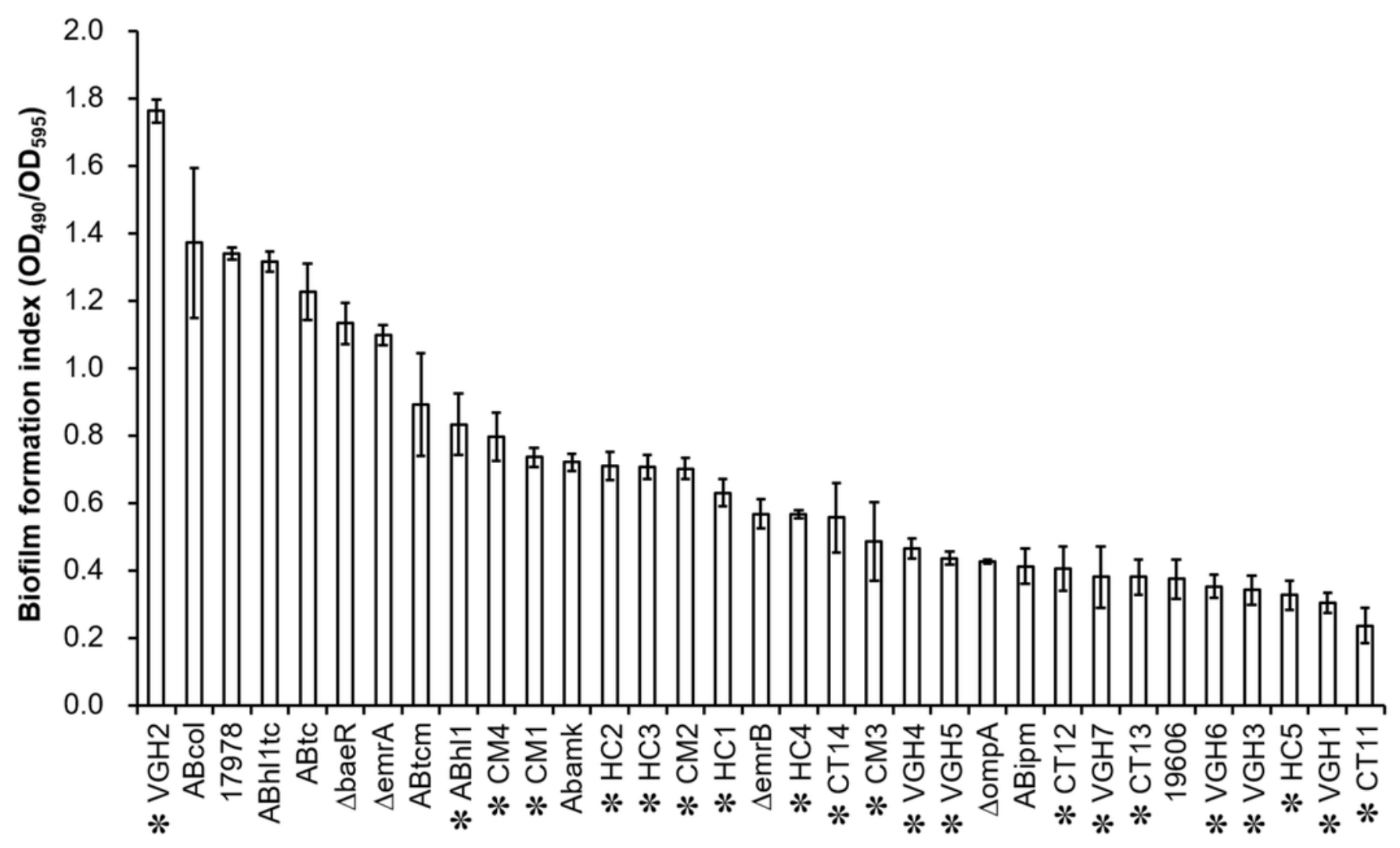




\section{Figure 2}

Comparison of the biofilm formation indices of the susceptible and resistant strains to the individual antibiotics among A. baumannii ATCC 17978 and 21 clinical isolates.

(A-O) The antimicrobial susceptibility of $A$. baumannii isolates was mainly determined according to the MIC interpretive criteria published by the CLSI in 2012 (M100-S22). The MICS of individual antibiotics against the clinical isolates were shown in Table S1. No relationship with statistical significance was demonstrated between the ability to form biofilm and the antimicrobial susceptibility of the $A$. baumannii clinical isolates. The Student's t-test ( $p$ $<0.05$ ) was used to determine the statistical significance of the experimental data. Abbreviations: SAM=ampicillin/sulbactam; TZP=piperacillin/tazobactam; CFZ=cefazolin; $C M Z=$ cefmetazole; $C T X=$ cefotaxime; $C A Z=$ ceftazidime; $F E P=$ cefepime; IPM=imipenem;

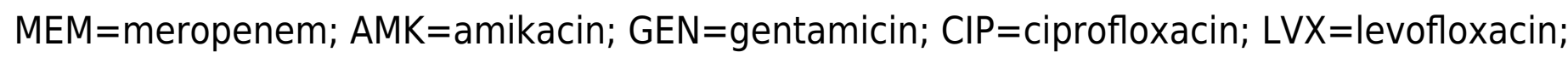
$\mathrm{SXT}=$ trimethoprim/sulfamethoxazole; $\mathrm{TGC}=$ tigecycline; $\mathrm{NE}=$ not evaluated; $\mathrm{S}=$ susceptible; $\mathrm{R}=$ resistant; $\mathrm{BFI}=$ biofilm formation index. 

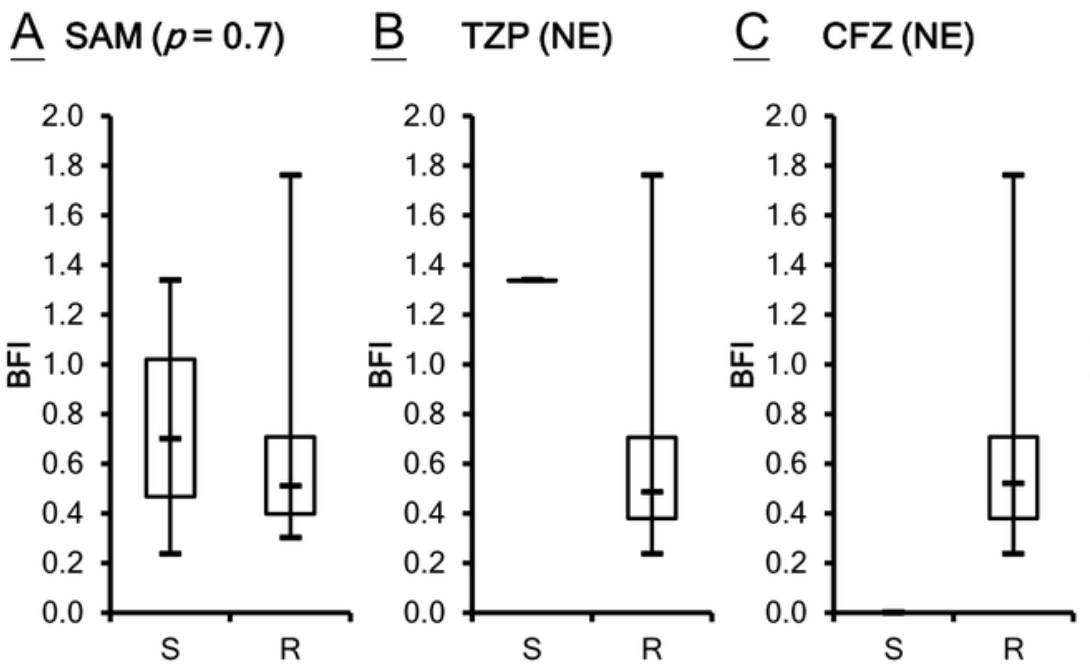

D $\quad \operatorname{CMZ}(\mathrm{NE}) \quad \underline{E} \quad \mathrm{CTX}(\mathrm{NE})$

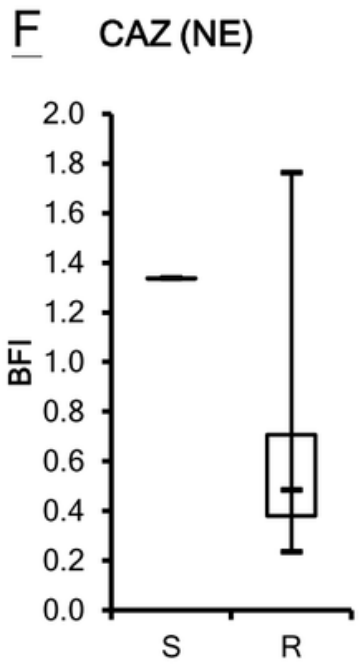

G $\operatorname{FEP}(\mathrm{NE})$

$\underline{\mathrm{H}} \operatorname{IPM}(p=0.8)$
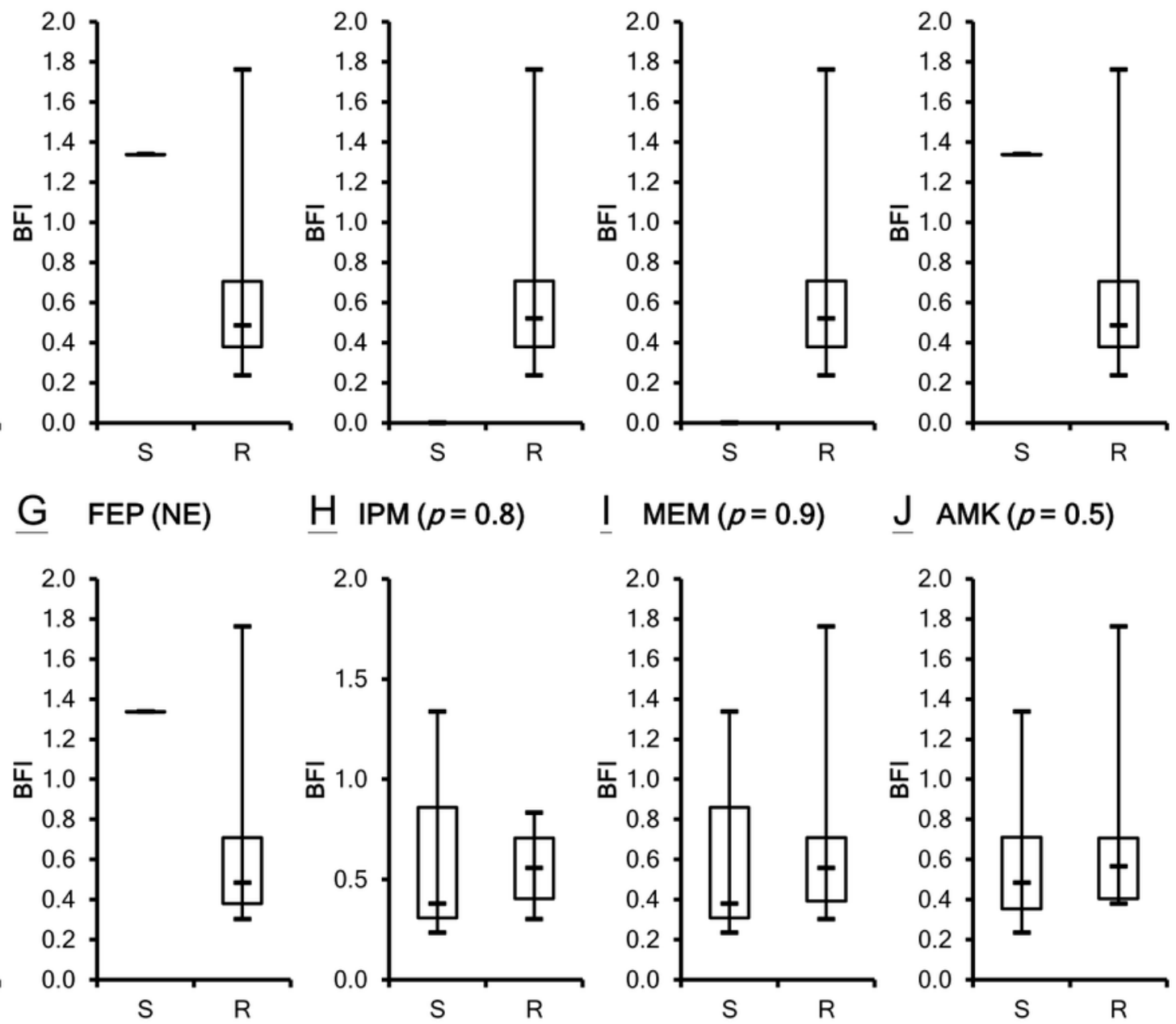

$\underline{\mathrm{K}} \operatorname{GEN}(p=0.5)$

L $\quad$ CIP (NE)

$\underline{\mathrm{M}} \operatorname{LVX}(p=0.4)$

$\underline{\mathrm{N}} \operatorname{sXT}(p=0.1)$

O $\operatorname{rGC}(p=0.7)$
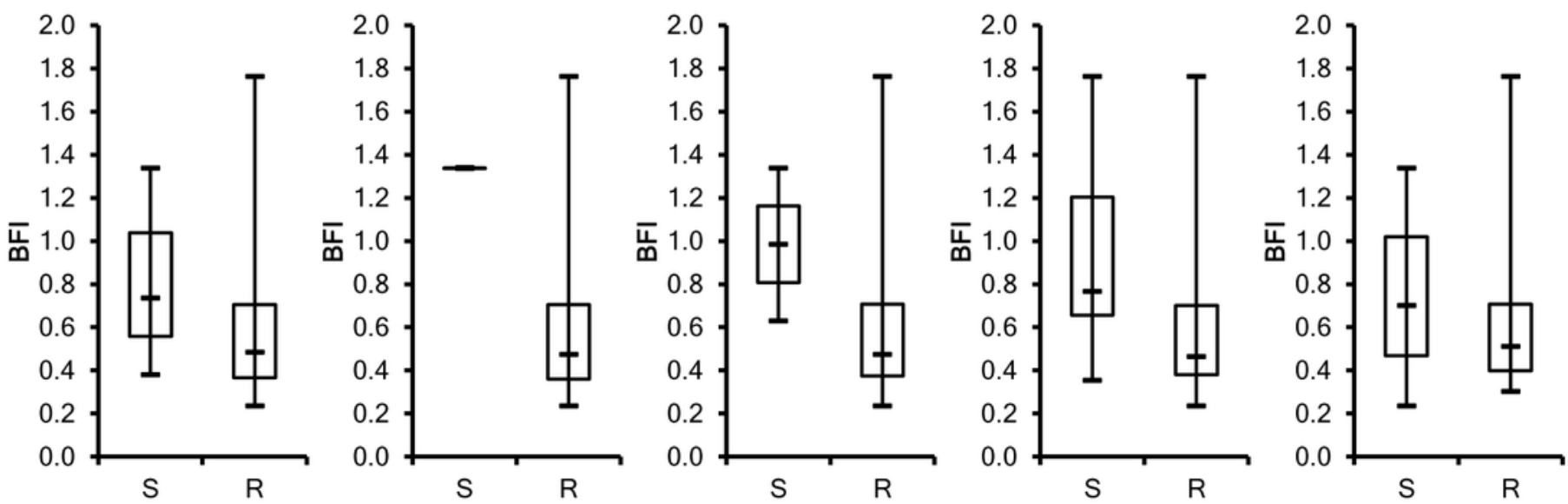


\section{Figure 3}

Biofilm formation by A. baumannii ATCC 17978 after gene knockout; (A) comparison between the wild-type stain and its mutants (B-E) SEM and (F-Q) CLSM images.

$\triangle b a e R, \triangle e m r A, \triangle e m r B$ and $\triangle o m p A$ all had less biofilm formation than the wild type. The results are shown as the means \pm SD from three independent experiments. The Student's ttest was used to determine the statistical significance of the experimental data. $*, p<0.05$ and $* *, p<0.01$ and ***, $p<0.001$ between ATCC 17978 and the gene knockout mutant strains. 

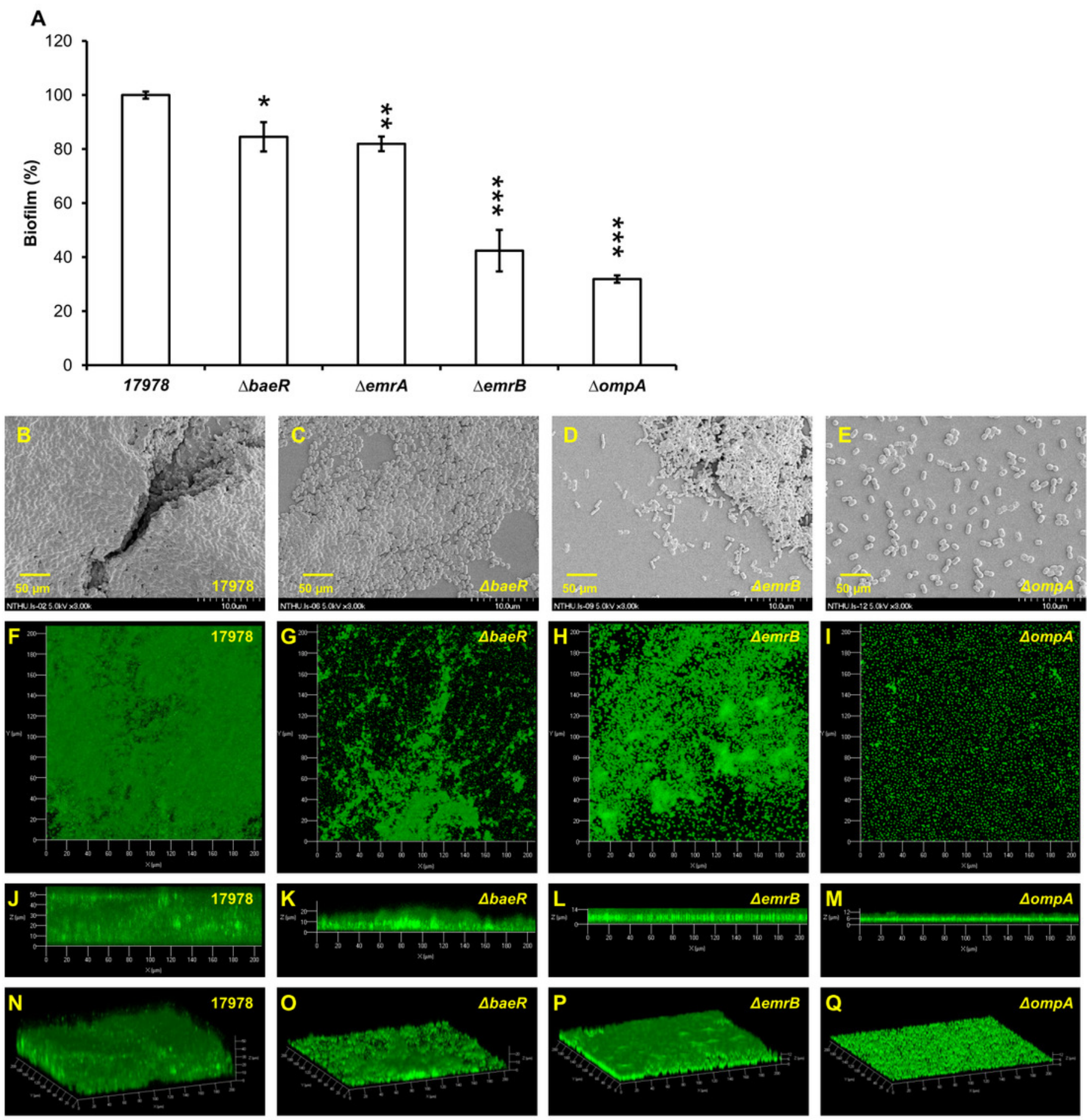


\section{Figure 4}

Influence of different compounds on biofilm formation in A. baumannii ATCC 17978; (A) amikacin, (B) imipenem, (C) colistin, (D) tigecycline, (E) LL-37, and (F) tannic acid.

The addition of amikacin (>0.5 $\mu \mathrm{g} / \mathrm{mL})$, colistin (>0.5 $\mu \mathrm{g} / \mathrm{mL})$, LL-37 (> $4 \mu \mathrm{g} / \mathrm{mL})$, or tannic acid ( $>50 \mu \mathrm{g} / \mathrm{mL}$ ) decreased the biofilm formation ability of $A$. baumannii ATCC 17978, whereas the addition of tigecycline ( $>62.5 \mathrm{ng} / \mathrm{mL}$ ) increased the biofilm formation ability of A. baumannii ATCC 17978. The Student's t-test was used to determine the statistical significance of the experimental data. $*, p<0.05$ and $* *, p<0.01$ and $* * *, p<0.001$ between A. baumannii ATCC 17978 with and without chemical compounds. 
A

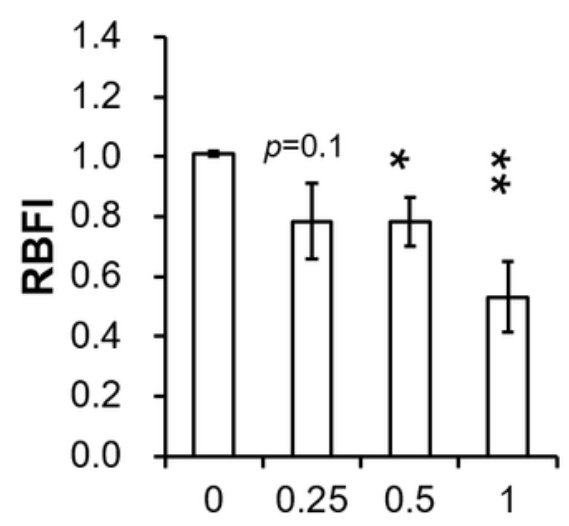

$\mu \mathrm{g} / \mathrm{mL}$

D

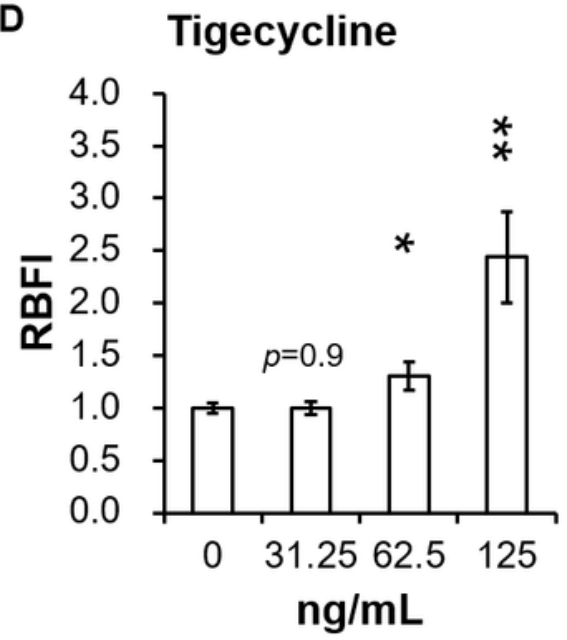

B

Imipenem

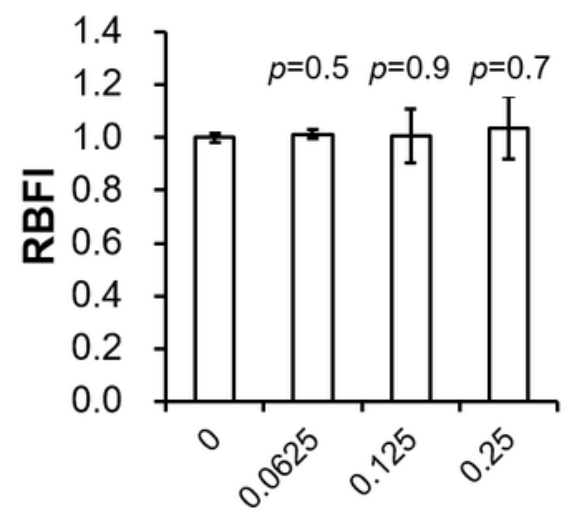

$\mu \mathrm{g} / \mathrm{mL}$

E

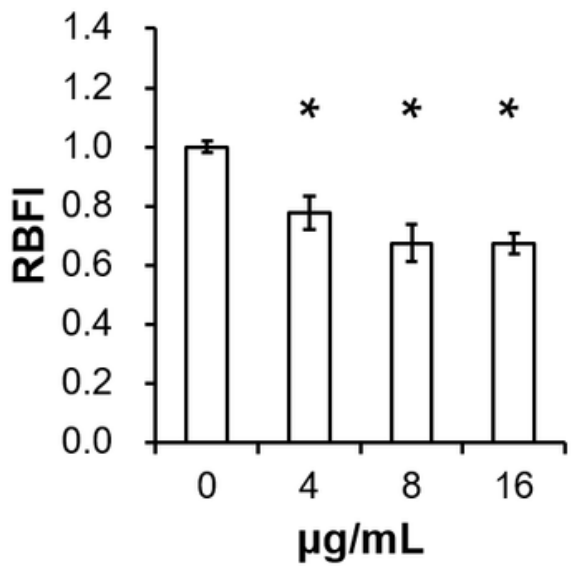

C Colistin

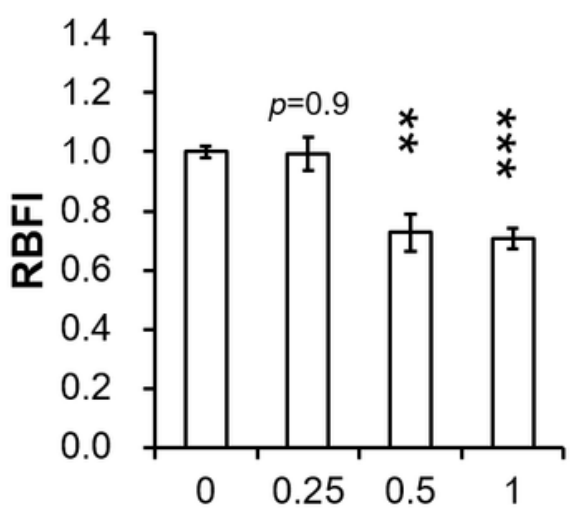

$\mu \mathrm{g} / \mathrm{mL}$

F Tannic Acid

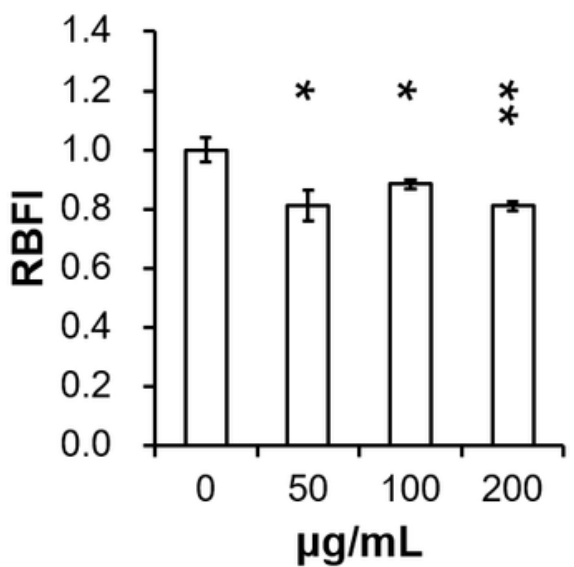




\section{Figure 5}

Influence of different compounds on biofilm formation in A. baumannii VGH2; (A) amikacin, (B) imipenem, (C) colistin, (D) tigecycline, (E) LL-37, and (F) tannic acid.

The addition of amikacin ( $>256 \mu \mathrm{g} / \mathrm{mL})$, imipenem ( $>4 \mu \mathrm{g} / \mathrm{mL}$ ), colistin $(>0.125 \mu \mathrm{g} / \mathrm{mL})$, LL-37 (> $2 \mu \mathrm{g} / \mathrm{mL}$ ), or tannic acid ( $>50 \mu \mathrm{g} / \mathrm{mL}$ ) decreased the biofilm formation ability of VGH2, whereas the addition of tigecycline $(>0.5 \mu \mathrm{g} / \mathrm{mL})$ increased the biofilm formation ability of VGH2. The Student's t-test was used to determine the statistical significance of the experimental data. $*, p<0.05$ and $* *, p<0.01$ between $A$. baumannii VGH2 with and without chemical compounds. 
A

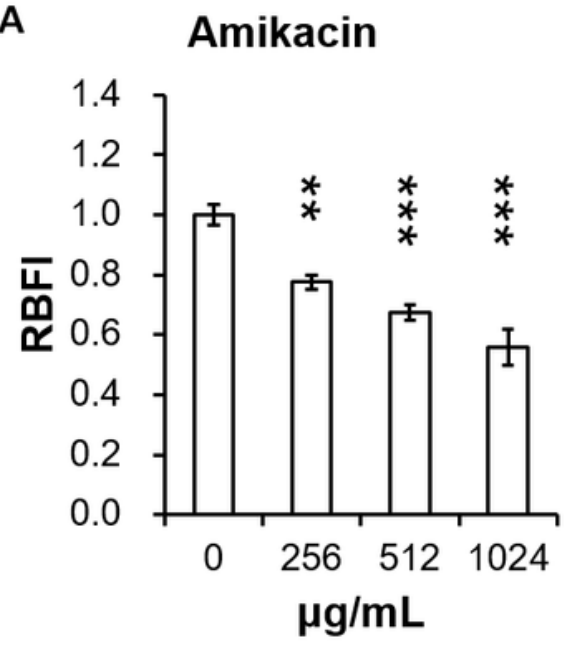

D

Tigecycline

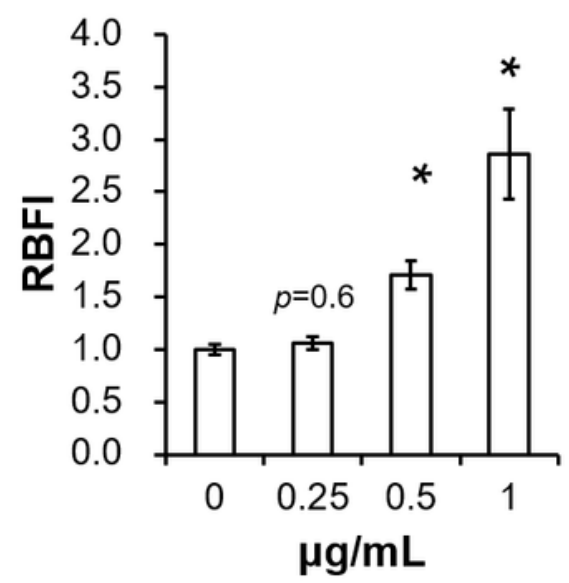

B

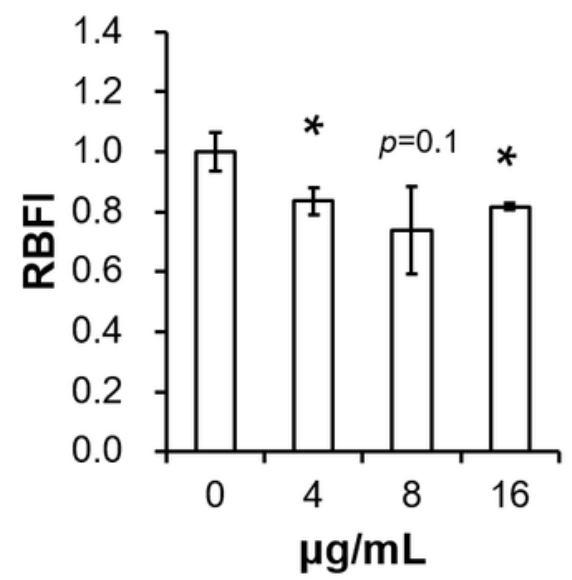

E

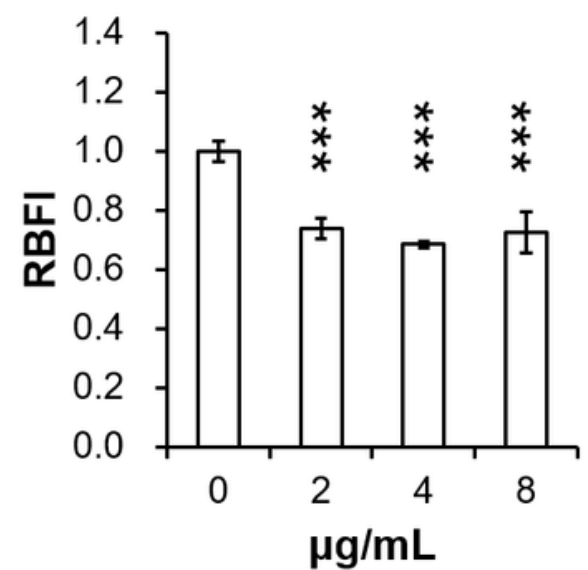

C

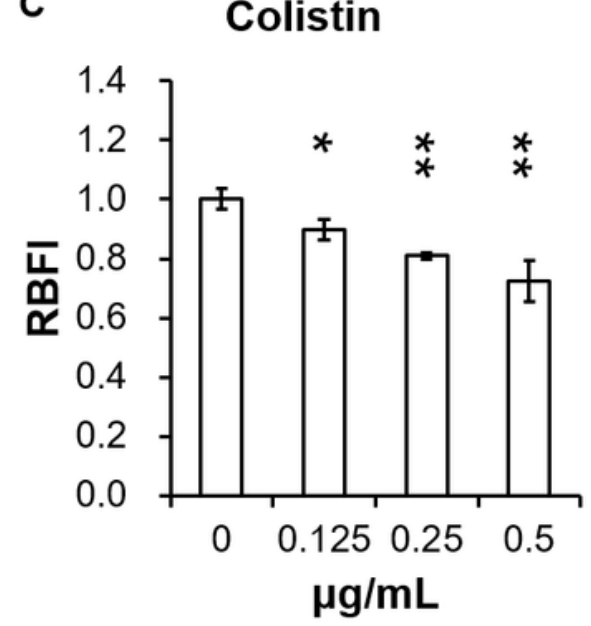

F

Tannic Acid

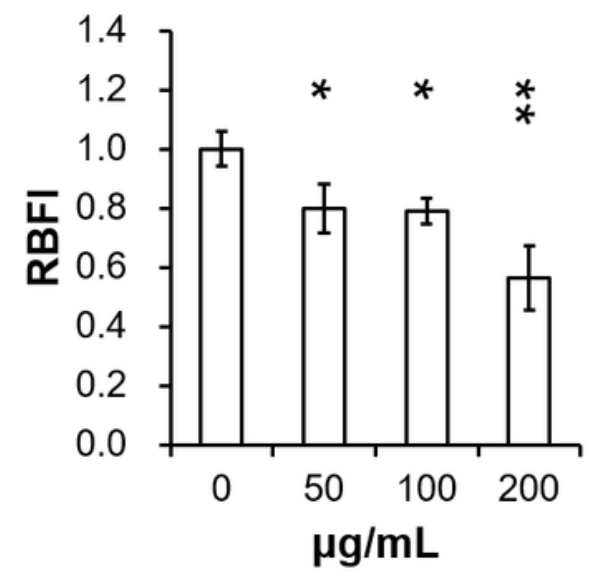


Figure 6

SEM and CLSM images of biofilm formation by A. baumannii ATCC 17978 after colistin and tigecycline challenge, (A-F) SEM and (G-O) CLSM.

The SEM image shows the cells become scattered and the CLSM images exhibit decreased thickness of biofilm. In contrast, $125 \mathrm{ng} / \mathrm{mL}$ tigecycline exposure has the opposite impact on biofilm formation of $A$. baumannii ATCC 17978. 

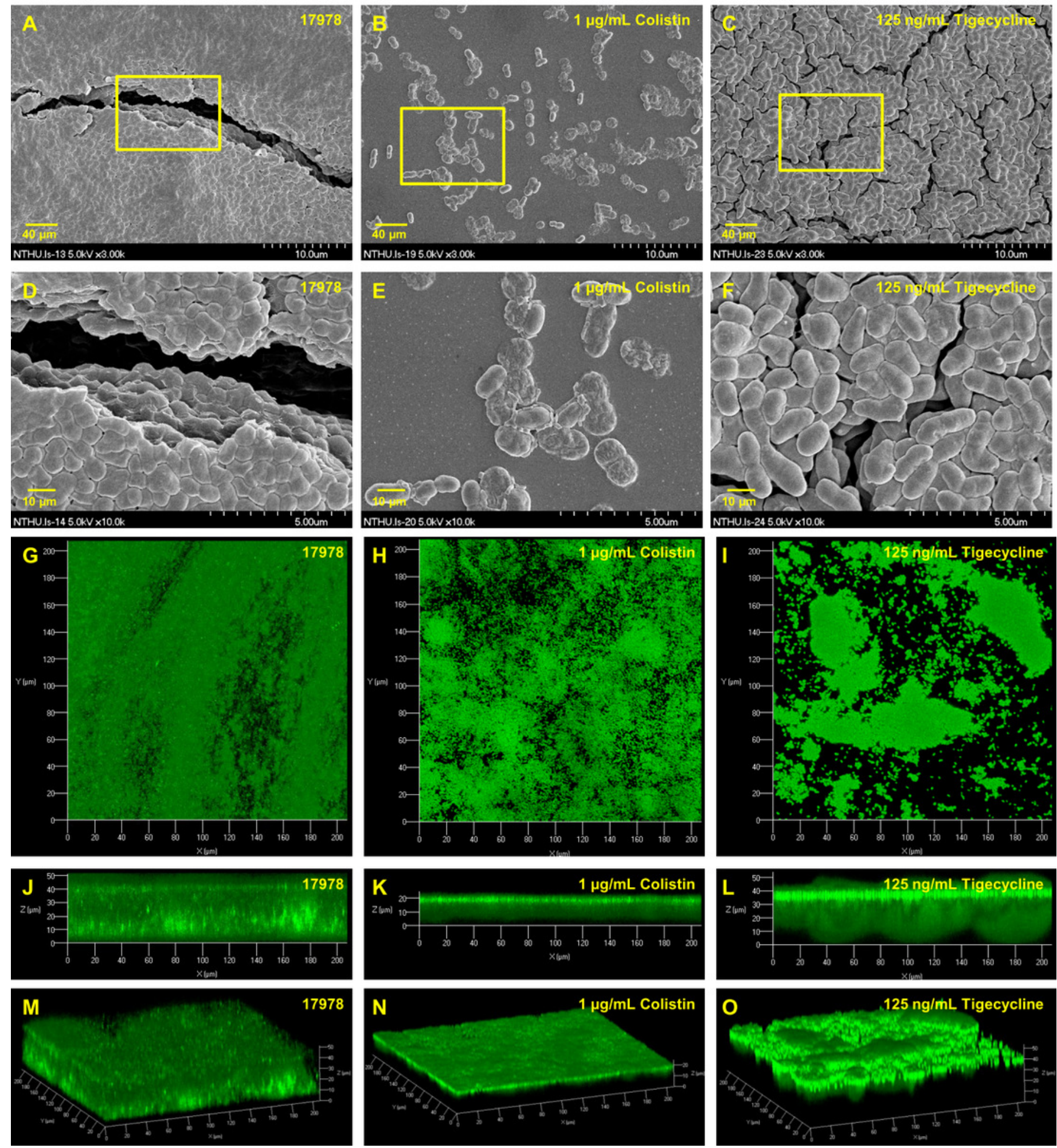


\section{Table $\mathbf{1}$ (on next page)}

Bacterial strains used in this study. 
2 Table 1. Bacterial strains used in this study

\begin{tabular}{|c|c|c|}
\hline Strain & Relevant feature(s) & $\begin{array}{l}\text { Source or } \\
\text { reference }\end{array}$ \\
\hline 19606 & A. baumannii Wild-type strain & ATCC \\
\hline 17978 & A. baumannii Wild-type strain & ATCC \\
\hline$\Delta b a e R$ & $\begin{array}{l}\text { Derived from ATCC 17978. baeR mutant obtained by } \mathrm{kan}^{r} \text { gene } \\
\text { replacement }\end{array}$ & $\begin{array}{l}\text { (Lin et al. } \\
\text { 2014) }\end{array}$ \\
\hline$\triangle e m r A$ & $\begin{array}{l}\text { Derived from ATCC 17978. A1S_1800 mutant obtained by } \mathrm{kan}^{r} \\
\text { gene replacement }\end{array}$ & $\begin{array}{l}\text { (Lin, Lin } \\
\& \text { Lan } \\
2017 a)\end{array}$ \\
\hline$\Delta e m r B$ & $\begin{array}{l}\text { Derived from ATCC } 17978 \text {. A1S_1772 mutant obtained not by } \mathrm{kan}^{r} \\
\text { gene replacement }\end{array}$ & $\begin{array}{l}\text { (Lin, Lin } \\
\& \text { Lan } \\
2017 a)\end{array}$ \\
\hline$\triangle o m p A$ & $\begin{array}{l}\text { Derived from ATCC 17978. ompA mutant obtained by } \mathrm{kan}^{r} \text { gene } \\
\text { replacement }\end{array}$ & $\begin{array}{l}\text { (Lin et al. } \\
\text { 2015) }\end{array}$ \\
\hline ABamk & Induced amikacin resistant ATCC 17978 & $\begin{array}{l}\text { (Lin et al. } \\
\text { 2017b) }\end{array}$ \\
\hline ABipm & Induced imipenem resistant ATCC 17978 & $\begin{array}{l}\text { (Lin et al. } \\
\text { 2017b) }\end{array}$ \\
\hline ABcol & Induced colistin resistant ATCC 17978 & $\begin{array}{l}\text { (Lin et al. } \\
2017 b)\end{array}$ \\
\hline ABtc & Induced tigecycline resistant ATCC 17978 & $\begin{array}{l}\text { (Lin et al. } \\
\text { 2014) }\end{array}$ \\
\hline ABtcm & Derived from ABtc. baeR mutant obtained by $\mathrm{kan}^{r}$ gene replacement & $\begin{array}{l}\text { (Lin et al. } \\
\text { 2014) }\end{array}$ \\
\hline ABhll & Tigecycline resistant clinical isolate from Hualien Tzu Chi Hospital & $\begin{array}{l}\text { (Lin et al. } \\
\text { 2014) }\end{array}$ \\
\hline ABhlltc & ABhl1 with induced high tigecycline resistance & $\begin{array}{l}\text { (Lin, Lin } \\
\& \text { Lan } \\
2015)\end{array}$ \\
\hline CT11-14 & $\begin{array}{l}\text { MDRAB isolate from the Chut-Tung branch of National Taiwan } \\
\text { University Hospital }\end{array}$ & $\begin{array}{l}\text { (Lin et al. } \\
\text { 2017b) }\end{array}$ \\
\hline CM1-4 & MDRAB isolate from Catholic Mercy Hospital & $\begin{array}{l}\text { (Lin et al. } \\
2017 b)\end{array}$ \\
\hline $\mathrm{HC} 1-5$ & $\begin{array}{l}\text { MDRAB isolate from the Hsin-Chu branch of National Taiwan } \\
\text { University Hospital }\end{array}$ & $\begin{array}{l}\text { (Lin et al. } \\
\text { 2017b) }\end{array}$ \\
\hline VGH1-7 & $\begin{array}{l}\text { MDRAB isolate from the Hsin-Chu branch of Taipei Veterans } \\
\text { General Hospital }\end{array}$ & $\begin{array}{l}\text { (Lin et al. } \\
2017 b)\end{array}$ \\
\hline
\end{tabular}




\section{Table 2 (on next page)}

MIC and MBEC of A. baumannii ATCC 17978 and VGH2. 
1

2 Table 2. MIC and MBEC of A. baumannii ATCC 17978 and VGH2.

\begin{tabular}{lcccc}
\hline & \multicolumn{2}{c}{ ATCC 17978 } & \multicolumn{2}{c}{ VGH2 } \\
\cline { 2 - 5 } & MIC & MBEC & MIC & MBEC \\
\cline { 2 - 5 } Amikacin $(\mu \mathrm{g} / \mathrm{mL})$ & 1 & 32 & 1024 & $>8192$ \\
Imipenem $(\mu \mathrm{g} / \mathrm{mL})$ & 0.25 & 1 & 16 & 512 \\
Colistin $(\mu \mathrm{g} / \mathrm{mL})$ & 1 & $>8192$ & 0.5 & $>8192$ \\
Tigecycline $(\mu \mathrm{g} / \mathrm{mL})$ & 0.5 & 2 & 4 & 32 \\
LL37 $(\mu \mathrm{g} / \mathrm{mL})$ & 16 & ND & 8 & ND \\
Tannic acid $(\mu \mathrm{g} / \mathrm{mL})$ & $>300$ & ND & $>300$ & ND \\
\hline
\end{tabular}

3 ND: Not detected 